$\begin{array}{ll} & \text { Etnográfica } \\ \text { etnográfica } & \text { Revista do Centro em Rede de Investigação em }\end{array}$

Antropologia

vol. $13(1) \mid 2009$

Vol. $13(1)$

\title{
Alcoolismo: doença e significado em Alcoólicos Anônimos
}

Alcoholism: illness and meaning in Alcoholics Anonymous

\section{Edemilson Antunes de Campos}

\section{(2) OpenEdition}

Journals

Edição electrónica

URL: https://journals.openedition.org/etnografica/1243

DOI: 10.4000/etnografica. 1243

ISSN: 2182-2891

\section{Editora}

Centro em Rede de Investigação em Antropologia

\section{Edição impressa}

Data de publição: 2 maio 2009

Paginação: 103-124

ISSN: 0873-6561

\section{Refêrencia eletrónica}

Edemilson Antunes de Campos, «Alcoolismo: doença e significado em Alcoólicos Anônimos»,

Etnográfica [Online], vol. 13 (1) | 2009, posto online no dia 16 maio 2012, consultado o 10 fevereiro 2022. URL: http://journals.openedition.org/etnografica/1243 ; DOI: https://doi.org/10.4000/ etnografica. 1243

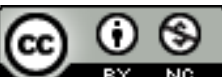

Etnográfica is licensed under a Creative Commons Attribution-NonCommercial 4.0 International License. 


\section{Alcoolismo: doença e significado em Alcoólicos Anônimos}

\section{Edemilson Antunes de Campos}

O objetivo deste artigo é o de compreender o modelo terapêutico construído pela irmandade de Alcoólicos Anônimos (AA) para dar conta da chamada "doença do alcoolismo", por meio de uma análise dos códigos culturais que operam no processo saúde-doença. A partir de uma pesquisa etnográfica feita em grupos de AA localizados na periferia da cidade de São Paulo - Brasil -, faz-se uma análise dos significados atribuídos à experiência do alcoolismo, com ênfase na linguagem que permite aos alcoólicos encontrar um sentido para suas aflições. O modelo de AA opera a construção simbólica da doença alcoólica e, por essa via, os alcoólicos encontram um sentido para o mal que os aflige, recuperando as relações familiares e profissionais perdidas no tempo do alcoolismo ativo.

PALAVRAS-CHAVE: Alcoólicos Anônimos, alcoolismo, cultura, grupos de auto-ajuda, processo saúde-doença.

\section{O OBJETIVO DESTE ARTIGO É O DE COMPREENDER O MODELO} terapêutico construído pela irmandade de Alcoólicos Anônimos ${ }^{1}$ para dar conta da chamada doença do alcoolismo, por meio de uma análise dos códigos culturais que operam no interior do processo saúde-doença. Trata-se de apreender a lógica por meio da qual os membros de AA elaboram uma representação específica de si mesmos, reconhecendo-se como "doentes alcoólicos em recuperação", responsáveis pelos cuidados de si mesmos e de suas famílias.

O alcoolismo é considerado um dos mais sérios problemas de saúde pública da atualidade, despertando a atenção de autoridades médicas e sanitárias de

1 Nas páginas seguintes, seguindo a maneira pela qual os membros de Alcoólicos Anônimos se referem à irmandade, utilizarei a sigla AA para me referir à irmandade dos Alcoólicos Anônimos e AAs quando me referir a seus membros. 
diversos países. Segundo as informações disponíveis, ${ }^{2}$ 12,3\% da população brasileira são dependentes do álcool, e a prevalência da dependência está na faixa etária de 18 a 24 anos, em um total de 19,2\% (Cebrid 2006: 41).

Mas, se é certa a prevalência do problema do alcoolismo nos dias atuais, ainda são raros os trabalhos, no âmbito das ciências sociais, especialmente no Brasil, que se ocupam tanto do chamado uso "patológico" de bebidas alcoólicas quanto das estratégias terapêuticas utilizadas pelos AAs para dar conta da "doença alcoólica", mesmo sendo conhecido o fato de que "o Brasil é um dos países com maior número de grupos de AA no mundo" (Soares 1999: 15). ${ }^{3}$

Em geral, nas ciências sociais o alcoolismo aparece como tema tangencial em estudos preocupados com a compreensão das formas e maneiras de beber, de modo que o ato de beber é entendido, sobretudo, como um ato social (Machado da Silva 1978; Dufour 1989; Guedes 1997; Bernand 2000; Magnani 2003), sinalizando os contextos nos quais o uso do álcool é valorizado e nos quais opera como uma espécie de "lubrificante social" (Neves 2004: 9), favorecendo a construção de laços de reciprocidade, constitutivos dos espaços de sociabilidade.

Ora, a equação alcoolismo/doença pode se revelar um importante objeto de estudo, notadamente quando os próprios pesquisados entendem o alcoolismo como doença. Assim, tomar o alcoolismo como "doença" não significa necessariamente ratificar o modelo biomédico, porque este pode ser o ponto de vista dos entrevistados, tal como ocorre, por exemplo, em AA

Durante suas reuniões, os ex-bebedores se reconhecem como "doentes alcoólicos": "Sou um doente alcoólico em recuperação e venho às reuniões para deixar de ser aquele cachaceiro que eu era", dizem os AAs, assinalando a passagem de uma posição na qual o beber considerado abusivo é estigmatizado para uma posição na qual o ato de beber é entendido de maneira "patológica".

Nessa medida, o par alcoolismo/doença é relativizado e entendido dentro de um contexto cultural específico. Os grupos de AA podem, então, ser compreendidos como um universo social, com seus ritos, representações, símbolos e valores próprios, que proporciona aos seus membros tanto a possibilidade de reorganizarem suas condutas como a de atribuírem significados próprios ao "problema" do alcoolismo, ao mesmo tempo em que constroem uma representação específica de si mesmos.

2 Segundo dados do II Levantamento Domiciliar sobre o Uso de Drogas Psicotrópicas no Brasil, realizado em 2005 pelo Centro Brasileiro de Informações sobre Drogas Psicotrópicas (Cebrid), da Universidade Federal de São Paulo (Unifesp), em conjunto com a Secretaria Nacional Anti Drogas (Senad), envolvendo as 108 maiores cidades brasileiras.

3 É importante ressaltar, contudo, os esforços empreendidos nos últimos anos em programas de pós-graduação de vários institutos vinculados às universidades brasileiras, com o intuito de preencher essa lacuna, através do estímulo a pesquisas focalizadas na equação alcoolismo/doença e, sobretudo, na atuação dos grupos de Alcoólicos Anônimos (cf. Campos 2005a; 2005b; Garcia 2004; Mota 2004). 
A noção de cultura é entendida, aqui, como uma unidade simbólica, isto é, uma ordem de sentido a partir da qual os sujeitos constroem os conteúdos significativos sobre sua existência. ${ }^{4}$ Opera-se, assim, com uma definição próxima daquela que Sahlins atribui à vida social culturalmente ordenada, sintetizada na expressão "razão simbólica", que toma como a "qualidade decisiva da cultura $[\ldots]$ não o fato de essa poder conformar-se a pressões materiais, mas o fato de fazê-lo de acordo com um esquema simbólico definido, que nunca é o único possível" (Sahlins 2003a: 7-8).

Seguindo essa linha, este trabalho aborda o problema do alcoolismo de uma maneira êmica, isto é, a partir do modo como ele é vivido e superado por aqueles que se reconhecem como "doentes alcoólicos em recuperação". Em outras palavras, busca-se entender a maneira através da qual os AAs abordam o alcoolismo, como eles o explicam, o vivenciam e tentam superá-lo, concebendo-o como uma "doença crônica e fatal" que afeta o conjunto das relações sociais - familiares e profissionais - nas quais o indivíduo que se considera doente está envolvido.

Trata-se de lançar um olhar socioantropológico sobre o alcoolismo, de maneira que o modelo terapêutico de AA é concebido como um constructo simbólico no interior do qual os significados da experiência com o álcool e do alcoolismo são construídos. Com isso, busca-se compreender a lógica que rege o modelo de AA, isto é, tanto a maneira como os AAs orientam suas práticas, tendo em vista sua recuperação, como as categorias que compõem a "linguagem" da doença, por meio da qual eles edificam um significado para a experiência do alcoolismo e que lhes permite orientar suas ações em direção a um cuidado de si mesmos e ao resgate dos laços familiares e profissionais rompidos nos tempos do alcoolismo ativo.

4 É importante frisar que a noção de cultura que a toma como uma unidade simbólica e que utilizamos para analisar o modelo de AA não deve negligenciar as relações que os "sistemas simbólicos", próprios das sociedades complexas, mantêm uns com os outros. Nesse sentido, cabe lembrar, como faz Guedes, "que qualquer cultura se realiza na permanente atualização e recriação deste sistema de diferenças, o que inclui as diversas possibilidades de sua própria modificação [...] só podendo ser cristalizada e isolada analiticamente" (1997: 26). De outro lado, é preciso também reconhecer a existência, dentro de uma determinada unidade de análise, de outros conteúdos significativos, próprios a outros sistemas de significação. Ainda segundo Guedes, "a acumulação de trabalhos antropológicos em sociedades complexas tem acentuado o problema de fazer corresponder um determinado sistema simbólico a uma unidade sociológica que o realize exclusiva e prioritariamente, não faltando, para a correlação feita, em termos empíricos, contra-exemplos incisivos que apontam quer as possibilidades de extensão dos significados analisados a outras unidades sociológicas, quer a presença, na unidade recortada, de significados outros, não estritamente vinculados àquele sistema analiticamente distinguido" (1997: 27). 


\section{ENCONTRANDO OS ALCOÓLICOS ANÔNIMOS}

Meu encontro com os Alcoólicos Anônimos 5 ocorreu por intermédio de um amigo que, durante uma conversa, na qual eu relatava meu interesse em fazer uma pesquisa sobre o programa de recuperação do alcoolismo desenvolvido pela entidade, disse-me conhecer um grupo próximo à sua residência, localizada na Vila Ema, pertencente ao populoso distrito de Sapopemba, ${ }^{6}$ na Zona Leste da cidade de São Paulo. Ele também me disse que os AAs se reuniam todas as noites e que poderia lhes fazer uma consulta sobre a possibilidade de eu realizar minha pesquisa ali. ${ }^{7}$ Após ele ter consultado os membros do grupo, marcamos um dia para minha ida ao local.

No dia marcado, encontrei-o na estação do metrô Belém e seguimos de ônibus para a sede do grupo. O percurso levou cerca de uma hora, e eu estava preocupado com a pontualidade - é importante ressaltar que todas as reuniões em que tive a possibilidade de participar começaram pontualmente às $20 \mathrm{~h}$-, pois não queria me atrasar em meu primeiro encontro. ${ }^{8}$

O itinerário percorrido foi revelando a paisagem típica das periferias das grandes cidades latino-americanas. Posteriormente, percorrendo as ruas do distrito, foi possível discernir traços importantes de sua formação social. O distrito de Sapopemba localiza-se em uma região limítrofe ao parque industrial do ABC, conhecido pela grande concentração de indústrias do setor automobilístico. Essa proximidade, decisiva para a configuração social do distrito, foi responsável pelo fluxo migratório, a partir dos anos 1950, de um grande contingente populacional, atraído pela promessa de melhores condições de vida.

5 A pesquisa de campo foi realizada entre setembro de 2001 e setembro de 2002 no grupo Sapopemba de AA, que faz parte do 42. ${ }^{\circ}$ distrito de Alcoólicos Anônimos do Estado de São Paulo, do Setor A - Capital. A escolha desse grupo deveu-se ao fato de se tratar de um já consolidado na promoção de reuniões de recuperação, que acontecem desde sua fundação, em 16 de março de 1981.

6 Segundo dados do IBGE (Instituto Brasileiro de Geografia e Estatística) e da Fundação Seade (Fundação Sistema Estadual de Análise de Dados), órgão do governo do Estado de São Paulo, o distrito de Sapopemba é o segundo distrito da cidade de São Paulo em densidade populacional, contando, em 2004, com 286.857 habitantes (<www.seade.gov.br/produtos/msp/dem/dem9_008.htm>, acesso em 10/09/2007).

7 A irmandade de Alcoólicos Anônimos conta com 522 grupos em todo o Estado de São Paulo, organizados em 59 distritos, divididos em 10 regiões. No setor A (Capital), existem 202 grupos de AA, organizados em 21 distritos, segundo dados do Escritório de Serviços Locais - ESL/SP (<www.aa-areasp.org.br/sp/membros/grupos/main.php>, acesso em 27/04/2008).

8 A chegada à sede do grupo de AA momentos antes do horário de início das reuniões foi fundamental para a pesquisa etnográfica, pois os momentos que antecedem a reunião nos ensinam muito das práticas de sociabilidade desenvolvidas entre os membros do grupo com o intuito de reforçarem seus laços, possibilitando sua identificação com a identidade de "doentes alcoólicos em recuperação".

9 A chamada região do ABC é um importante pólo industrial brasileiro e compreende as cidades de Santo André, São Bernardo do Campo e São Caetano do Sul, localizadas no Estado de São Paulo. Durante os anos de 1980, essa região se destacou pela presença de um forte movimento operário que se engajou na luta pela redemocratização da sociedade brasileira. 
O bairro concentra uma população majoritariamente trabalhadora, que depende do próprio salário para sua reprodução social, e assemelha-se, em sua forma, aos bairros vizinhos, delineando os contornos de uma paisagem composta por casas simples, ou inacabadas, ou em processo de construção, e que servem de local de moradia, ao mesmo tempo, para a própria família e para a de seus filhos, quando estes vêm a se casar.

Além de abrigo para o núcleo familiar, a casa tem, muitas vezes, um outro papel importante, funcionando como local de atividade econômica, na maioria das vezes informal, um recurso utilizado como forma de aumentar a renda familiar. ${ }^{10}$ São pequenos estabelecimentos que oferecem os mais variados serviços, tais como conserto de sapatos, venda de salgadinhos, cabeleireiro, costureira, serviços de pedreiro, conserto de geladeiras, de ferro de passar roupas, etc.

A queda do número de empregos formais ${ }^{11}$ foi responsável por colocar um contingente expressivo de trabalhadores da região na situação de risco de perda do emprego, aumentando a fragilidade econômica em que vivem. Percorrendo a Avenida Sapopemba, que atravessa, em sua longa extensão, todo o distrito, é possível constatar o aumento da atividade informal pelo grande número de barracas de vendedores ambulantes que se distribuem em suas calçadas.

Viver no distrito de Sapopemba também permite formular uma visão própria sobre a vida nas periferias das grandes metrópoles:

Eu percebo que nosso bairro é periferia. Então, na periferia, é aquela dificuldade, a maioria da população toda desempregada. [...] Eu, como sou daqui, cheguei aqui no bairro em 1970, já faz um bocado de anos que eu faço parte desta comunidade [...] Eu vejo que não existe um lazer na região, o lugar mais próximo é no parque do Carmo. Eu vejo uma dificuldade de condução. Aqui em Sapopemba não tem um posto de saúde.

No olhar de um membro de AA, o bairro aparece, assim, classificado como periferia, cuja condição se define através das dificuldades compartilhadas cotidianamente, dentre as quais se destacam o desemprego e a falta de infra-estrutura de transporte e saúde, tornando mais difícil a luta pela sobrevivência.

Segundo recorte feito a partir dos dados oficiais, relativos ao ano de 2002, o distrito não contava com equipamentos culturais tais como, por exemplo,

10 Segundo dados do IBGE e da Fundação Seade, referentes ao Censo de 2000, 61,38\% dos habitantes do distrito de Sapopemba vivem com uma renda familiar que oscila na faixa de dois a menos de dez salários mínimos. Já 18,08\% da população vivem com renda familiar inferior a dois salários mínimos (<www.seade.gov.br/produtos/msp/ren/renl_001.htm>, acesso em 10/09/2007).

11 Segundo dados da Pesquisa de Emprego e Desemprego da Fundação Seade, a região de Sapopemba contava, em 2006, com uma taxa de desemprego de 13,2\% entre as pessoas acima de 16 anos, com uma prevalência de 16,09\% entre os jovens na faixa de 16 a 29 anos (<www.nossasaopaulo.org.br/observatorio/analises.php?tema $=11$ \&indicador $=49 \&$ ano=2006\#info $>$, acesso em 23/04/2008). 
salas de cinema, salas de teatro, casas de cultura, centros de cultura, museus e espaços e oficinas culturais. ${ }^{12}$ Todavia, circulando por suas ruas, é possível visualizar uma sociabilidade que se desenvolve em espaços de lazer, os quais instauram uma alteridade em relação ao espaço doméstico e ao local de trabalho. Esse é o caso, por exemplo, dos bares, que, em números expressivos, povoam suas esquinas e ruas. O bar aparece, muitas vezes, como uma das poucas alternativas de lazer para os moradores da região.

O distrito abriga ainda uma escola de samba - Combinados de Sapopemba -, da qual fazem parte alguns membros de AA e cujos ensaios para o carnaval mobilizam os moradores em seus momentos de lazer. No mês de junho ocorre o aniversário do distrito, que é comemorado em uma grande festa - a Festa de Sapopemba -, engajando seus moradores nos preparativos necessários à sua organização e realização.

Há também uma igreja católica, centros espíritas e terreiros de umbanda, que convivem com uma quantidade crescente de igrejas evangélicas, instaurando um circuito religioso pelo qual seus moradores circulam, participando de atividades que, muitas vezes, concorrem com as poucas opções de lazer oferecidas na região. A igreja católica também abriga reuniões de Narcóticos Anônimos e do Al-Anon, irmandades paralelas, dirigidas aos dependentes de drogas e aos familiares e amigos de dependentes do álcool, respectivamente. Não raro, também é possível ver algum membro de AA durante a missa, fazendo a divulgação das reuniões do grupo.

Durante a pesquisa, foi possível constatar, no chamado "livro de registro" ${ }^{13}$ e, também, em conversas com o coordenador e com o responsável pela manutenção da sala de reuniões do grupo Sapopemba, um total de 86 pessoas registradas como membros ingressantes no grupo. Destes, 81 são homens e 5 mulheres. A presença maciça de homens é uma característica marcante dos grupos de AA, o que também foi confirmado por Garcia (2004: 57-60) em sua pesquisa no grupo Doze Tradições, localizado no município de São Gonçalo, no Estado do Rio de Janeiro.

Segundo as informações colhidas, dos 86 ingressantes, 37 se afastaram do grupo: 36 homens e uma mulher. A grande rotatividade de membros é outra

12 Dados em <www.seade.gov.br/produtos/msp/cul/cull_002.htm>, acesso em 10/09/2007.

13 Embora não faça um controle rigoroso da freqüência às atividades, o grupo Sapopemba mantém um "livro de registro" no qual são anotados os nomes dos membros quando de sua entrada no grupo e, também, daqueles veteranos que continuam participando das suas reuniões. Os AAs me disseram que esse livro deve sua existência à "autonomia do grupo", que pode decidir manter um controle desse tipo, caso seus membros julguem necessário. Eles disseram, ainda, que, através desse livro, é possível saber a média de membros que freqüentam o grupo, facilitando o repasse da contribuição do grupo aos órgãos de serviços da irmandade. Além do livro de registro, há também um "livro de freqüência", que os membros assinam todos os dias quando chegam para as reuniões. 
característica presente no cotidiano da irmandade. ${ }^{14}$ No caderno de ingresso, é possível constatar que daqueles membros que se afastaram, 15 ficaram no grupo de 1 a 6 meses, 13 ficaram de 7 a 12 meses, 7 ficaram de 13 a 18 meses e 2 ficaram de 19 a 24 meses. Em um prazo de um ano, constata-se que 28 pessoas se afastaram do grupo.

Já em relação aos membros que mantêm um vínculo permanente com a irmandade, segundo os registros mantidos pelo grupo, constata-se que 11 membros têm até um ano de tratamento no grupo, 17 têm entre 2 e 5 anos, 2 têm entre 6 e 10 anos e 9 têm entre 11 e 15 anos, 7 têm entre 16 a 20 anos e 3 têm mais de 20 anos.

Por meio da observação das atividades do grupo e também dos registros feitos em seu livro de presença, constatou-se que nas reuniões de recuperação há uma freqüência média de 15 membros. Entre aqueles com os quais conversei, 18 no total, apenas um tem menos de 40 anos. Os demais estão em uma faixa etária que varia entre 40 e 73 anos.

A elevada faixa etária dos AAs parece ser um indicador de que a "maturidade física" favorece a percepção das perdas acumuladas durante o chamado tempo do "alcoolismo ativo", na medida em que o uso considerado abusivo do álcool provoca efeitos danosos não só ao organismo do alcoólico, mas, sobretudo, à sua família. Voltaremos a esse tema. Por hora, cabe reter que a elevada faixa etária parece também ser um indício da percepção do elo existente entre os planos físico e moral que envolve a "doença do alcoolismo".

Entre os membros que contatei, ${ }^{15}$ é significativo o número de aposentados (6), os quais ainda continuam trabalhando em atividades informais, chamadas de "bicos", como forma de obter alguma renda. Destacam-se também cinco membros que não têm vínculo empregatício formal: um marceneiro, dois pedreiros, um sapateiro e um taxista. Em número menor (3), estão os que têm um emprego formal: um assistente administrativo, um motorista e um zelador. Entre as mulheres, duas são "donas de casa", como elas próprias se consideram, uma é funcionária pública e uma está aposentada.

A associação do uso de álcool às massas trabalhadoras constitui uma referência consagrada no âmbito das pesquisas relativas aos sistemas de classificação e

14 Garcia (2004: 60-61) observa que, no grupo Doze Tradições, no ano de 2002, 5 membros não chegaram a completar um mês de permanência; 4 atingiram 9 meses; 18 estão entre 1 e 9 anos; 11 têm entre 10 e 19 anos; e 4 têm 20 e 29 anos de permanência. Os motivos aventados para o afastamento de um membro do grupo são, segundo comentários feitos por aqueles que permanecem, as chamadas "recaídas", situação em que o alcoólico volta a beber, a mudança para outros grupos ou a busca por outras opções de tratamento.

15 Como não foi possível entrevistar todos os membros do grupo, os dados apresentados referem-se àqueles membros com os quais mantive contato nos dias em que participava das reuniões de recuperação. 
às relações de poder, que visam estabelecer formas de controle social sobre os membros das camadas populares (Neves 2004: 11 ). ${ }^{16}$

Contudo, ao se priorizar a escolha de um grupo de AA sediado em um bairro popular, não se pretendeu, com isso, deduzir os significados elaborados em torno da doença do alcoolismo da condição social de seus membros. Trata-se sim, metodologicamente, de analisar, a partir de um caso concreto, o modo como a fala da doença articula e mobiliza elementos do universo social no qual os AAs estão inseridos, permitindo-lhes atribuir um sentido à experiência do alcoolismo, ao mesmo tempo que definem uma compreensão própria de si mesmos.

Durante os depoimentos, os AAs destacam, sobretudo, as perdas acumuladas na vida em família, durante o período ativo do alcoolismo. A esfera familiar revela-se, assim, uma referência fundamental para os membros do grupo, de maneira que a maioria deles se declarou casada. Entre os homens, nove se declararam casados, três solteiros e um viúvo. Entre as mulheres, duas se declararam casadas e duas viúvas. À exceção dos solteiros, os demais declararam todos que têm filhos.

A metodologia de pesquisa contou, fundamentalmente, com a realização de entrevistas e com a observação de diversas atividades promovidas pela irmandade dos Alcoólicos Anônimos. Foram observadas as reuniões de recuperação, além de outras atividades promovidas pelo grupo, tais como encontros, reuniões de serviços, reuniões de unidade, reuniões temáticas, festas comemorativas do aniversário do grupo, etc. Nesses encontros, os AAs narram uns aos outros, em verdadeiros depoimentos pessoais, feitos em primeira pessoa e chamados de "partilhas", suas experiências vividas antes e depois da entrada em AA.

Já as entrevistas foram individuais e semi-estruturadas, e aconteceram, em sua maior parte, em 2001 e 2002. Como forma de se obter um melhor controle sobre os dados coletados, realizamos outras, no final do ano 2004 e início do de 2005. Ao longo da pesquisa de campo, também foram entrevistados familiares de um dos AAs, sua esposa e suas duas filhas, com a finalidade de avaliar as representações elaboradas sobre o álcool, o alcoolismo e o programa de AA e suas repercussões na vida familiar de um alcoólico. Essas foram as únicas entrevistas fora da sala do grupo.

As entrevistas individuais e com os familiares dos alcoólicos foram fundamentais para a pesquisa, pois permitiram uma aproximação mais intensa

16 Para Neves (2004), um eixo de análise muito recorrente é aquele que associa o uso do álcool às massas trabalhadoras, enfatizando as situações de precariedade socioeconômica, aglutinado-se em torno da equação "pobreza, precariedade e alcoolismo", acabando por legitimar intervenções sobre esse contingente da população. Com efeito, "de um modo positivo, a associação tende a valorizar a relação entre precárias e adversas condições de trabalho e o uso sistemático ou abusivo de álcool. De um modo negativo, a associação tende a consagrar a articulação entre o uso abusivo de bebida alcoólica e a imprevidência individual, incompatível com desempenhos de papéis de esposo, companheiro e pai" (Neves 2004: 11). 
aos membros do grupo. Com efeito, se, nas reuniões, foi possível delimitar a linguagem da doença no interior do modelo terapêutico fornecido pela irmandade, nas entrevistas individuais foi possível estabelecer um maior controle sobre as informações obtidas, de maneira a compreender o modo como os alcoólicos elaboram uma compreensão própria do modelo de AA e de como este repercute em suas vidas, possibilitando formular um sentido para a experiência do alcoolismo.

\section{ALCOOLISMO, DOENÇA E SUBJETIVIDADE EM ALCOÓLICOS ANÔNIMOS}

Alcoólicos Anônimos são, de acordo com sua literatura oficial, "uma irmandade de homens e mulheres que compartilham suas experiências, forças e esperanças, a fim de resolver seu problema comum e ajudar outros a se recuperarem do alcoolismo" (Alcoólicos Anônimos 1996). ${ }^{17}$ Trata-se de um programa de recuperação, expresso nos Doze Passos e nas Doze Tradições (Alcoólicos Anônimos 2001), ${ }^{18}$ cujo objetivo é ajudar os alcoólicos a evitar o "primeiro gole" e, assim, manter a "sobriedade".

Seu modelo terapêutico é voltado, fundamentalmente, à recuperação individual e pessoal de seus membros, que "parecem ter perdido o poder para controlar suas doses ingeridas" (Alcoólicos Anônimos 1996). O alcoolismo é entendido como uma "doença incurável, progressiva e fatal", de base "física e espiritual", que se caracteriza pela "perda de controle sobre o álcool", levando o alcoólico a beber de maneira compulsiva, podendo, com isso, conduzi-lo à "loucura" ou à "morte prematura".

O modelo terapêutico da irmandade conta ainda com a participação dos AAs em reuniões periódicas, cujo objetivo é também ajudá-los a evitar o "primeiro gole" e, assim, a manter a sobriedade. As reuniões podem ocorrer em salas alugadas ou cedidas por igrejas, escolas, instituições correcionais ou de tratamento.

17 A irmandade de Alcoólicos Anônimos nasceu em 1935, em Akron, no Estado de Ohio, nos Estados Unidos, após uma conversa entre um corretor da Bolsa de Nova Iorque e um médico, ambos conhecidos, respectivamente, como Bill Wilson e Bob Smith. Eles constataram que, por alguma razão até ali não bem compreendida, conseguiam ficar sem beber durante bons períodos depois que passavam algum tempo conversando e compartilhando seu problema. Após vivenciar uma verdadeira "experiência espiritual e experimentar fortes sentimentos de triunfo, paz e serenidade", segundo depoimento do próprio corretor, ele decidiu trabalhar para que outros alcoólicos beneficiassem com a descoberta e montou os primeiros grupos.

18 O programa de recuperação de AA baseia-se em um conjunto de procedimentos voltados ao aprimoramento "espiritual" do indivíduo considerado doente. De um lado, esse programa terapêutico inclui a admissão de que existe um problema, a busca de ajuda, a auto-avaliação, a partilha em nível confidencial e a disposição tanto para reparar os danos causados a terceiros como para trabalhar com outros alcoólicos que desejem se recuperar. De outro lado, estão inclusas as relações que os AAs mantêm entre si e com a sociedade em geral, estas reguladas a partir de um conjunto de preceitos que garantem a unidade da irmandade. A reunião desses dois pólos forma a espinha dorsal do programa de recuperação de AA, também chamado de programa dos "Doze Passos e das Doze Tradições". 
As chamadas "reuniões de recuperação" podem ser de dois tipos: "fechadas", compostas apenas por aqueles que se consideram "doentes alcoólicos", e "abertas", destinadas a todos aqueles que desejam conhecer a irmandade.

Nessas reuniões, compartilham suas experiências, ajudando-se mutuamente a encontrarem forças para superar a "doença alcoólica". Assim, quando chegamos a uma sala de AA, seja para, por curiosidade, conhecer as atividades do grupo, seja para buscar ajuda para o "problema" do alcoolismo, somos apresentados a um conjunto de idéias e de procedimentos formulados, dizem seus membros, para dar conta da "doença do alcoolismo" e ajudá-los a manter a sobriedade. Os AAs são unânimes em dizer que "aprenderam" isso depois que chegaram ao grupo: "Quando cheguei aqui, aprendi que era doente e impotente em relação ao álcool. Fiz minha parte e me mantenho sóbrio. Venho para não esquecer que não posso beber."

Os membros de AA encontram na irmandade um conjunto de valores que orientam suas práticas no sentido de sua recuperação. Eles "aprendem" que são "doentes", e que devem evitar o "primeiro gole". Constrói-se, assim, uma teoria do alcoolismo na qual o indivíduo não é o responsável pela aquisição de sua "doença", mas ao contrário a remete ao terreno da fatalidade e da aleatoriedade.

Essa perspectiva se coaduna com a visão exposta na literatura de AA, que define o alcoolismo como o resultado de uma articulação entre uma "sensibilidade física ao álcool" e "uma obsessão mental" em ingerir bebida alcoólica, que impede o alcoólico de parar de beber. Para AA, é possível ser um alcoólico sem jamais ter bebido, bastando, para isso, não ter tido contato com a bebida alcoólica. Foi o que me disse um membro de AA, quando afirmou: "existem pessoas aí que nasceu, viveu aí 80 anos, ele é um alcoólatra só que ele nunca ficou bêbado. Por quê? Porque ele nunca entrou em contato com bebida alcoólica. É essa predisposição orgânica."

A literatura antropológica tem enfatizado que a teoria da doença de AA representa o alcoolismo nos termos de uma "théorie de l'inné" (Fainzang 1996: 34), própria a uma tradição biologizante largamente difundida nos Estados Unidos, segundo a qual ele é definido como uma "doença inata", de base "genética", enraizada no organismo do alcoólico. Trata-se de uma "maladie de longue durée" (Saliba 1982: 82); uma doença crônica de base orgânica e mental que independe da "força de vontade" do alcoólico para sua superação e controle.

Todavia, é necessário avançarmos na compreensão dos significados ligados à definição do alcoolismo concebido como uma "doença incurável e fatal". Ora, os AAs têm uma maneira própria para traduzir essa característica da doença alcoólica, expressa na proposição semântica "um alcoólico não se torna alcoólico, ele é alcoólico".

Além de reforçar a idéia de que se é portador de uma "doença crônica", essa proposição sintetiza aquilo que Bateson (1977) chama de o "objetivo 
perseguido" no modelo de AA, qual seja "o de permitir que o alcoólico coloque seu alcoolismo no interior de si mesmo" (1977: 279, tradução minha). Trata-se de "incorporar" o alcoolismo, através da idéia de que se é portador de uma “doença incurável”, com a qual deve-se aprender a conviver. É exatamente isso o que se depreende da afirmação de um membro de AA:

Eu sou João, um doente alcoólico em recuperação. Eu agradeço ao Poder Superior, companheiros e companheiras, que me ajudam nessa recuperação. Sou portador da doença do alcoolismo, uma doença que tava guardada dentro de mim e que se manifestaria em qualquer ocasião em que eu tivesse contato com a bebida alcoólica. Eu poderia ter evitado tudo no mundo, mas um dia eu beberia, nem que fosse por curiosidade, e aí estaria a conseqüência.

$\mathrm{Na}$ troca de experiências durante a reunião de recuperação, a condição de doente é reiterada, através da lembrança permanente e repetida das experiências etílicas de cada indivíduo e do caminho rumo à sobriedade, ancorada nos instrumentos fornecidos pelo grupo. De acordo com Soares,

Contra a ameaça de que o esquecimento das condições de doente-alcoólico facilite a tentação do primeiro gole, contra o perigo de que a "negação" da incapacidade de controlar a bebida leve o alcoólatra a supor-se novamente senhor de sua vontade e capaz de prescindir do poder superior - e do grupo -, os AAs cultivam um inventário de experiências de que se valem tanto os novatos quanto o mais antigo veterano, jamais liberto por completo das armadilhas insidiosas de sua doença (1999: 260).

No modelo de AA, portanto, o alcoolismo é entendido como um mal que o indivíduo traz em si mesmo, que é parte dele, mas que pode ser controlado, desde que ele aceite a existência da doença e a impossibilidade de enfrentá-la sozinho: "O fato é que a maioria dos alcoólicos, por razões ainda obscuras, perde o poder de decisão diante da bebida. Nossa assim chamada 'força-devontade' torna-se praticamente inexistente [...] Não temos qualquer proteção contra o primeiro gole" (Alcoólicos Anônimos 1994: 47).

Ora, essa incapacidade de enfrentar o problema do alcoolismo seguindo apenas a própria vontade é traduzida no primeiro e segundo passos do programa de recuperação da irmandade (Alcoólicos Anônimos 2001):

1) Admitimos que éramos impotentes perante o álcool - que tínhamos perdido o domínio sobre nossas vidas;

2) Viemos a acreditar que um Poder Superior a nós mesmos poderia nos devolver à sanidade. 
O alcoólico deve reconhecer que é portador de uma doença, que independe da "força de vontade" para seu controle. Ao invés de afirmarem "eu posso", "eu quero" e "eu consigo", tal como prevê a crença arraigada na soberania do eu, assente na ideologia moderna do individualismo, frente ao reconhecimento de seu fracasso na condução de sua própria vida pela vontade, ele reconhece sua "impotência" diante de uma doença que é fatal, e que necessita de ajuda.

Esses passos representam, assim, um momento fundamental para a reconstrução da subjetividade, através do reconhecimento de que o indivíduo não é uno, mas antes múltiplo, pois há nele forças que o guiam e o controlam, independentes do ego. Com efeito, assiste-se a uma subjetivação da doença alcoólica, isto é, a uma construção subjetiva marcada pela patologia do alcoolismo.

Mais do que pertencer a uma tradição biologizante, o modelo de AA opera como um constructo que instaura um peculiar regime de alteridade, a partir de um mecanismo simbólico de incorporação da doença, que passa a ser entendida como a "alteridade" presente no corpo de cada alcoólico. Nessa linha, o modelo de AA possibilita a instauração de um regime prático-discursivo dentro do qual os AAs se reconhecem como "doentes alcoólicos em recuperação": indivíduos doentes que trazem o mal dentro de si.

Um dos membros de AA enuncia nos seguintes termos esse processo de "incorporação" da doença:

Eu só olho o grupo na minha frente. É uma coisa gostosa. É um Poder Superior maravilhoso que me traz aqui todos os dias. Eu não consigo mais viver sem a sala de AA Na hora da reunião, tem uma coisa que incorpora em mim. Eu não tenho vontade de beber, o que é importante. Hoje eu sou um cara feliz, porque eu não bebo cachaça.

Os AAs constroem uma rede de reciprocidade, no interior da qual atualizam sua condição de doentes. Eles só podem assumir a doença alcoólica, para si mesmos, se esta for reafirmada diante dos outros alcoólicos durante as reuniões. Não é por acaso, então, que o membro de AA diz que na hora da reunião "tem uma coisa" que o "incorpora", que passa a fazer parte dele. Trata-se do reconhecimento da doença, da internalização da condição de doente, reafirmada cotidianamente dentro do grupo.

Nas reuniões vivenciadas na irmandade, assiste-se à construção da identidade de "doente alcoólico em recuperação", através de um processo simbólico no qual a doença é percebida como um "outro" cuja morada é o próprio corpo do alcoólico. O indivíduo encontra, dessa maneira, um lugar para o corpo e para o espírito, ambos enfermos, reconciliando-se consigo mesmo e também com seus familiares. Esse é o passo fundamental dado pelos AAs na direção de sua reconstrução subjetiva, cujos contornos são delineados a partir do 
reconhecimento da doença como alteridade que é coletivizado nas histórias de vida compartilhadas todos os dias.

A troca de experiências contribui para criar uma memória coletiva, um repertório comum que fortalece a adesão ao modelo terapêutico e a conseqüente disposição de se evitar o uso do álcool. Em vez de ficar no esquecimento, a sobriedade é mantida pela lembrança sempre repetida das desventuras com a bebida vividas por cada um dos membros do grupo. Os AAs cultivam, assim, um inventário de experiências comuns que serve de antídoto à tentação do "primeiro gole", de maneira que tomam para si a responsabilidade pelo controle da "doença alcoólica".

A fala de cada membro é um fio que se entrelaça com os outros na construção de uma verdadeira rede de reciprocidade, que serve de referência ao conjunto da irmandade. Como conseqüência, garante-se a continuidade da instituição, através da (re)produção de suas idéias e valores a partir de uma prática cotidiana que possibilita a adesão de novos adeptos, que encontram em AA um lugar onde o corpo e o espírito considerados "enfermos" têm os recursos e o suporte necessários à sua recuperação.

\section{ALCOOLISMO: UMA DOENÇA ENTRE O FÍSICO E O MORAL}

A reunião de recuperação é o momento no qual os homens e as mulheres membros de AA compartilham suas experiências individuais - histórias de vida do tempo de alcoolismo ativo e da recuperação -, falam também de seus conflitos, perdas e conquistas, atualizando os princípios que presidem ao programa de recuperação da irmandade (Campos 2005a: 95-1 16).

Nessas reuniões, os alcoólicos narram uns aos outros, em verdadeiros depoimentos pessoais feitos em primeira pessoa e chamados de "partilhas", suas experiências vividas antes e depois da entrada em AA. Através dessas narrativas de forte apelo emocional, eles se ajudam mutuamente, reforçando a identificação com os princípios da irmandade, ao mesmo tempo que encontram forças para manter a sobriedade, reorganizando suas vidas de uma maneira individual e coletiva.

É nas reuniões de recuperação que os membros do grupo podem (re)atualizar o modelo terapêutico da irmandade, comunicando e legitimando sua condição de "doente":

Meu nome é Aurélio, um doente alcoólico em recuperação que freqüenta as reuniões para deixar de ser bêbedo. Para deixar de ser cachaceiro [...] O Aurélio era compulsivo por cachaça. O álcool estava me dominando. Eu já tava completamente dominado pelo álcool. Na ativa, eu fui agressivo com minha saúde. Desenvolvi uma hipertensão. Quando bebia perdia tudo, deixava de lado a família, os amigos, o trabalho. Com AA consegui manter 
minha família, meus amigos. Agora tenho tudo [...] É preciso ter consciência da doença, do que ela causa.

Uma análise das partilhas feitas durante as reuniões de recuperação revela que, embora fundadas na experiência intransferível da dor e do sofrimento, elas utilizam um código comum e específico, uma linguagem para expressar os dilemas e embaraços da prática social e o confronto cotidiano entre as situações vividas e os valores próprios do contexto sociocultural em que vivem, notadamente os valores da família e do trabalho.

As narrativas colhidas durante a pesquisa de campo, no grupo Sapopemba de AA, também são eloqüentes na representação do alcoolismo como uma doença que comporta uma multiplicidade de significados, os quais deslizam entre os planos físico e moral. Quando falam sobre o alcoolismo, os AAs mobilizam um rico conjunto de categorias para expressarem suas aflições e os efeitos do álcool sobre seu organismo e, conseqüentemente, a sua deterioração. É o que encontramos nas entrevistas feitas com os membros do grupo:

Eu acordava de manhã e sentia aquelas dores na barriga, no estômago; eu precisava vomitar, e só depois que eu bebia aquilo passava [...] Eu comecei a ter ânsias às três horas da manhã, constantemente; mesmo se eu não tivesse bebido, vinha aquela ânsia. Me dava água na boca. Chegava oito e meia da manhã, não dava: e eu tinha que beber para ficar legal. Já tinha que beber. Eu já bebia de manhã mesmo. Eu era muito relaxado com meu físico.

Durante as partilhas é comum ouvirmos, ainda, que o alcoolismo provoca o "inchaço das mãos e das pernas", "ânsias e náuseas", "dores de barriga e de estômago" e "tremores" que só cessam após a ingestão de uma dose de bebida alcoólica. Os AAs traçam, então, uma nosografia da doença do alcoolismo a partir de "sintomas" orgânicos, tais como "ressaca”, "tontura", "náuseas", "perda de força física", "enfraquecimento", "tremores", "alergia”, "inchaço das mãos e do rosto", "hipertensão" e "cirrose".

Associado à sintomatologia orgânica, também encontramos um leque variado de expressões que se referem aos efeitos mentais do uso do álcool que alteram o comportamento do alcoólico, tais como "alucinações", "depressão", "desequilíbrio", “agitação", “agressividade”, "apagamento”, "delírios”, "nervoso", "perda de memória" e "loucura".

Ligada a essa sintomatologia física e mental, também se observa, na fala dos AAs, uma rica expressão de "sintomas" morais que apontam para os efeitos do alcoolismo no campo de relações nas quais o alcoólico está envolvido, notadamente no trabalho e na família.

Os membros do grupo evocam os efeitos do álcool e do alcoolismo sobre a família nos seguintes termos: "O bêbado é um ladrão da família"; "Eu tirava 
o prazer da família"; e "O alcoolismo é uma doença da família". A doença do alcoolismo extravasa os limites do indivíduo para afetar, sobretudo, o núcleo relacional no qual o alcoólico está inserido, conduzindo-o a uma ruptura de seus laços familiares e de trabalho: "Quando bebia perdia tudo e deixava de lado a família, os amigos, o trabalho"; "Quando bebia eu não via meus filhos, eu não me relacionava com minha mulher. Perdia tudo. Só queria a bebida."

Os AAs mobilizam um conjunto de expressões e de categorias morais que denotam uma forma própria de entender o alcoolismo e seus efeitos. Assim, a "doença alcoólica" é apreendida pelas categorias morais do "orgulho", "onipotência", "egocentrismo" e "ressentimento", que, por sua vez, provocam efeitos morais, tais como "sarjeta moral", "desequilíbrio moral”, "perda de força moral", "desmoralização", ou efeitos sociais como, por exemplo, "sarjeta social", "perda dos amigos", e ainda efeitos profissionais, definidos como "sarjeta profissional" e "perda do trabalho", para além de efeitos familiares, como "brigas do casal", "conflitos com os filhos", "perda da família" e "doença da família”.

$\mathrm{Na}$ linguagem da doença formulada pelos AAs, portanto, o alcoolismo assume os contornos de uma "perturbação físico-moral", ${ }^{19}$ afetando tanto o âmbito físico/orgânico como o âmbito relacional da família. A chamada doença do alcoolismo é traduzida tanto a partir de seus efeitos sobre o organismo, atingindo o âmbito físico e mental do doente, como a partir de seus efeitos sobre o plano moral, afetando, sobretudo, o âmbito relacional da família. Se o alcoolismo é uma "doença do indivíduo", ele é também uma "doença da família".

\section{O ALCOOLISMO É UMA “DOENÇA DA FAMÍLIA”}

A categorização do alcoolismo como uma "doença da família" possui um valor heurístico, uma vez que permite entrever os sentidos do adoecer e do sofrimento, fundados nos valores diferenciais que conformam o contexto sociocultural no qual os AAs estão envolvidos, notadamente os valores "família" e "trabalho". É isso o que se pode perceber na entrevista com um dos membros de AA:

O alcoolismo me afetou principalmente na família e no trabalho. Primeiro com a família, porque eu passei a ser aquele homem descompromissado; aquele homem com quem não se pode contar. Isso me criou um problema muito sério, pois a própria família não acreditava mais em mim, e

19 As perturbações "físico-morais" são entendidas, aqui, no sentido proposto por Duarte e dizem respeito "às condições, situações ou eventos de vida considerados irregulares ou anormais pelos sujeitos sociais e que envolvam ou afetem não apenas sua mais imediata corporalidade, mas também sua vida moral, seus sentimentos e sua auto-representação" (Duarte 2003: 177). 
eu também não. O alcoolismo me atrapalhava [...] Na fábrica foi a mesma coisa: eu tinha minhas atribuições junto aos demais companheiros, mas, de acordo com minha bebedeira, ninguém podia contar comigo. Eu passei a ser um homem inútil na equipe. E aí eu sinto que eu mesmo perdi o domínio, perdi a credibilidade, eu perdi o interesse, eu perdi a força de vontade, eu perdi a força física.

Fica claro que o alcoolismo afeta diretamente as relações que o alcoólico mantém na família e no trabalho. A dependência do álcool, que atinge o doente, abala a "força física" do alcoólico, que se vê incapaz de cuidar de si e de sua família. Com isso, ele não se reconhece mais com um "homem digno", isto é, com um trabalhador responsável por prover o sustento de sua família.

Mas, como a doença alcoólica se articula aos valores próprios ao universo sociocultural no qual os AAs estão inseridos, notadamente ao valor da família? Como o alcoolismo informa sobre as relações sociais nas quais os alcoólicos estão envolvidos?

A literatura antropológica tem evidenciado o papel central ocupado pela família nas relações sociais e na definição da identidade social, sobretudo entre os membros das camadas populares. Exemplo disso é o trabalho de Sarti, que destaca o modo como a família opera como uma referência simbólica central nos meios populares, de maneira que o espaço familiar, pensado "como uma ordem moral, constitui o espelho que reflete a imagem com a qual os pobres ordenam e dão sentido ao mundo social" (Sarti 2005: 22) no qual estão inseridos.

Duarte já havia destacado a centralidade que a família ocupa entre os membros das camadas populares, operando como um valor na construção da identidade social e da noção de pessoa no seu interior. Para esse autor, "o valor-família abarca um certo número de qualidades distribuídas entre seus componentes e que lhe concedem sua preeminência enquanto foco da identidade social" (Duarte 1986: 175). Nas camadas populares, portanto, o "valor-trabalho", fundamental na definição da condição de "trabalhador" e de "homem provedor", é encapsulado pelo "valor-família", centro irradiador e foco principal na definição da identidade dos membros desse grupo social.

Ora, mesmo sabendo que a irmandade de AA define o alcoolismo como uma "doença do indivíduo", quando falam do mal que os aflige, os AAs falam de si mesmos e dos conflitos vividos no meio social em que vivem. A fala da doença proporciona, então, uma linguagem através da qual os membros do grupo podem dar um sentido às suas aflições e aos conflitos enfrentados no âmbito relacional da família e do trabalho, que operam como valores estruturantes e englobantes do conjunto das práticas vivenciadas no meio social no qual os AAs estão inseridos.

Aqui, também é importante ouvirmos as palavras de Sahlins, para quem os significados produzidos no interior de uma ordem cultural são constantemente 
reavaliados pelos agentes em suas ações em confronto com o mundo: se, "por um lado, as pessoas organizam seus projetos e dão sentido aos objetos partindo das compreensões preexistentes da ordem cultural [...] Por outro lado, os homens criativamente repensam seus esquemas convencionais" (Sahlins 2003b: 7). ${ }^{20}$

A expressão "doença da família" indica, portanto, um modo particular de os AAs entenderem e significarem a experiência do alcoolismo no interior do modelo terapêutico da irmandade. Certa vez, em uma conversa com um membro de AA, indaguei se essa definição estava presente na literatura oficial da irmandade. Como resposta, ele me disse: "Não, isso você só encontra aqui [no grupo Sapopemba], essa é uma definição nossa."

A irmandade de AA opera como uma ordem de significação no interior da qual são construídos os significados em torno do álcool, do alcoolismo e de si mesmo, entendido como um "doente alcoólico em recuperação", de maneira que seus membros têm um modo próprio de significarem suas experiências etílicas, articulando e mobilizando elementos característicos do universo social no qual estão inseridos, notadamente os valores família e trabalho, que estruturam e orientam suas práticas sociais.

Para os AAs, o alcoolismo faz com que toda a família, e não apenas o alcoólico, adoeça, subvertendo a ordem familiar. ${ }^{21} \mathrm{Ou}$ seja, o alcoolismo é concebido como uma "doença da família", isto é, uma doença física e moral que envolve a totalidade da pessoa portadora deste mal, comprometendo a construção do alcoólico como um indivíduo "responsável”, impedindo-o de reconhecer-se nas identidades sociais de "pai/mãe", "esposo(a)" e "trabalhador(a)".

O portador da doença do alcoolismo vive uma "perda de controle sobre o álcool", o que significa, sobretudo, "perder a qualidade moral de cuidar de si e de prover sua família através do trabalho" (Campos 2005a: 133). É ainda o que nos diz um membro de AA, em entrevista, sobre o modo como a doença alcoólica afeta os laços sociais do doente:

20 Ainda segundo Sahlins, "Os homens em seus projetos práticos e em seus arranjos sociais, informados por significados de coisas e de pessoas, submetem as categorias culturais a riscos empíricos. Na medida em que o simbólico é, deste modo, pragmático, o sistema é, no tempo, a síntese da reprodução e da variação" (2003b: 10).

21 A categorização "doença da família" também sinaliza a dimensão "contagiosa" do alcoolismo, presente nas representações dos ex-bebedores e nas de seus familiares sobre os efeitos do álcool na esfera familiar. Como lembra Fainzang, uma doença não contagiosa do ponto de vista médico pode assumir um caráter contagioso nas representações formuladas por seus portadores. Nesse sentido, "a definição antropológica da idéia de contágio deve se liberar de suas dimensões médicas e dar conta das representações, as quais ela converte em objeto de estudo, visando propor uma nova acepção" (Fainzang 1996: 93, tradução minha). Em trabalho anterior (Campos 2005b: 315-361), discutimos a possibilidade de elaboração de uma "teoria cultural do contágio" a propósito do alcoolismo, distante das acepções biomédicas. 
Eu senti que eu estava dependendo do álcool e que estava decadente; foi quando, uma vez, eu cheguei em casa e não consegui abrir o portão para entrar, e dormi do lado de fora do portão. O pessoal que passava indo para o trabalho, eu lembro, um cara passou e apontou o dedo para mim, eu vi, eu estava acordado, só não tinha força para levantar; ele disse: “olha o bêbedo onde dormiu". Aí eu senti que minha situação estava triste.

Essa fala é emblemática sob vários aspectos. Fica claro, de um lado, como a "dependência do álcool" compromete a "força física" do bebedor, impedindo-o de se levantar e obrigando-o a dormir fora de casa. De outro, dormir na rua reforça o estigma pertencente à imagem do "bêbado" que não consegue entrar dentro da própria casa, em oposição à imagem do "trabalhador", do homem responsável, que acorda cedo para ir ao trabalho e prover o sustento de sua família.

Mas deixar de trabalhar significa, sobretudo, não cumprir seu papel moral de "homem provedor". Pois, "na moral do homem, ser homem forte para trabalhar é condição necessária, mas não suficiente para a afirmação de sua virilidade" (Sarti 2005: 95, grifos do original).

Dormir na rua, nos bancos de jardins e praças, também é um signo da ruptura com o suporte relacional da família, que dá ao alcoólico a possibilidade de se reconhecer como "homem digno". A casa confere uma forte dignidade moral àqueles que nela habitam. Nela, o homem é reconhecido como "pai", "esposo", "chefe de família" e toda uma ordem de categorias que, diferentemente da rua, lhe garantem autoridade e reconhecimento.

Como lembra Sarti, o uso do álcool pode comprometer, justamente, o exercício da "dignidade" do homem:

A casa é onde [se] realizam o projeto de ter uma família, permitindo [...] a realização dos papéis centrais na organização familiar, o de pai de família e o de mãe/dona-de-casa. Esse padrão ideal pressupõe o papel masculino de prover teto e alimento, do qual se orgulham os homens [...] Assim, para constituir a "boa" autoridade, digna da obediência que lhe corresponde, não basta ao homem pegar e botar comida dentro de casa e falar que manda. Para mandar, tem que ter caráter, moral. Assim, o homem, quando bebe, perde a moral dentro de casa. Não consegue mais dar ordens (Sarti 2005: 62-63, grifos do original).

$\mathrm{Na}$ entrevista acima, dormir na rua significa fazer parte de um mundo indiferenciado e impessoal, do "mundo da rua" no qual se é "ninguém". Na rua, ele não encontra mais o lugar da autoridade que exerce na família. Sua tristeza reflete o sentimento de "fracasso", por não cumprir com sua "obrigação" de prover sua família com "teto e alimento", uma vez que os homens se sentem 
responsáveis pelos rendimentos familiares. Trata-se, assim, do sentimento de "perda da dignidade" e do reconhecimento da "sarjeta moral" em que se encontra.

O alcoolismo assume, assim, toda a dimensão de uma doença que articula os planos físico e moral da pessoa, impedindo o alcoólico de agir de modo "responsável”. Quando falam da doença e dos dissabores enfrentados nos tempos do alcoolismo ativo, os AAs falam dos conflitos enfrentados com os valores e as regras da vida social, nas quais estão envolvidos, notadamente, os valores "família" e "trabalho".

\section{A LINGUAGEM DA DOENÇA ALCOÓLICA}

Mas qual é a lógica que rege o modelo terapêutico de AA para dar conta do alcoolismo? Os AAs elaboram uma linguagem da doença alcoólica, que lhes permite organizar e dar um sentido à experiência vivida, reconhecendo-se como "doentes alcoólicos". O alcoólico passa, assim, a cuidar de si mesmo, ao mesmo tempo que cuida de sua família, religando os fios que haviam sido rompidos na vida social: "Depois que eu conheci Alcoólicos Anônimos, eu passei a ter uma vida diferente. Depois de muito tempo separado, eu voltei a conviver. Hoje com meu trabalho, eu consigo manter minha família. É essa a condição que o AA dá."

O modelo terapêutico de AA conduz o alcoólico a mudar seu "modo de ser", e a seguir um outro "estilo de vida", longe dos "velhos amigos, dos velhos hábitos e dos velhos caminhos" vividos no tempo do alcoolismo ativo. Trata-se de uma reconstrução subjetiva por meio de um conjunto de práticas e de discursos que investem diretamente sobre seu corpo e seu espírito, possibilitando sua recuperação.

Não por acaso, o programa de recuperação da irmandade é chamado de "programa de evitações", sinalizando uma ressignificação dos espaços de sociabilidade no interior dos quais o ex-bebedor constrói sua experiência entre, de um lado, o "bar", o "boteco", "espaço da ativa", no qual as relações eram mediadas pelo uso de bebidas alcoólicas e, de outro, tanto o "grupo de AA", o "espaço da recuperação", como a "casa" e o "local de trabalho", espaços das relações familiares e profissionais, respectivamente, que são agora valorizados. Em entrevista, um membro de AA afirma:

Antes de Alcoólicos Anônimos eu só pensava no bar. Quando chegava do trabalho eu não parava cinco minutos em casa e já ia para o bar. Muitas vezes eu chegava em casa bêbado e nem tomava banho; dormia de qualquer jeito. Quando acordava era aquela ressaca [...] Hoje eu chego em casa beijo meus filhos, converso com eles, com minha mulher. Agora, por exemplo, eu estou 
pagando a formatura de minha filha. Hoje, sóbrio, eu consigo conversar com meus filhos. Tudo isso eu devo ao Poder Superior e a Alcoólicos Anônimos.

O modelo terapêutico de AA possibilita a recuperação do alcoólico, através do resgate de sua responsabilidade, ao mesmo tempo física e moral. Com efeito, ao contrário da deterioração do organismo provocada pelo álcool, assiste-se agora a uma valorização do cuidado da própria saúde, do bem-estar físico e estético, expresso "no cuidado em fazer a barba", "cortar os cabelos", "tomar banho" e no "vestir-se".

O mesmo ocorre também em relação ao âmbito moral, onde ao invés do "orgulho", o alcoólico cultiva a "humildade"; ao invés do "egoísmo", ele cultiva o "altruísmo"; ao invés da "hostilidade", ele cultiva a "amizade"; ao invés do "ressentimento", o alcoólico pratica a "ajuda" ao outro alcoólico que ainda sofre. É assim que o alcoólico recupera sua "dignidade" e se reconhece como "provedor" de sua família.

O modelo de AA é regido por uma lógica cuja regra enfatiza tanto os procedimentos terapêuticos dos cuidados de si - corporais, médicos, higiênicos e estéticos - como os códigos culturais que conformam o contexto sociocultural no qual os alcoólicos estão envolvidos. Em outras palavras, trata-se de uma lógica regida por uma "biomoralidade", isto é, uma forma específica de gestão da própria vida na qual o exercício da responsabilidade individual no cuidado de si mesmo se coaduna com uma lógica própria a uma forma de gestão coletiva da saúde, que envolve a recuperação das relações familiares dos membros da irmandade.

O modelo terapêutico de AA aponta para uma forma de gestão da saúde cuja lógica se organiza em torno do individual e do coletivo (familiar), visando "a integração de normas e práticas de tipo individualista à gestão coletiva da saúde" (Fassin 1996: 273, tradução minha). Ou seja, a lógica terapêutica dirigida ao cuidado de si é englobada pela lógica cultural, expressa por meio de uma linguagem da doença formatada em torno dos valores da "família" e do "trabalho", característicos do contexto sociocultural no qual os AAs estão inseridos.

Ora, o modelo de AA possibilita que o alcoólico reconstrua os vínculos familiares e profissionais, pelo cultivo de sua responsabilidade. Para os AAs, a responsabilidade não é uma categoria "ético-abstrata", mas sim a "responsabilidade-obrigação" para consigo mesmo e pelos atos cometidos nos tempos do alcoolismo ativo, sobretudo se esses atos provocaram danos a terceiros, que deverão, agora, ser reparados.

A "responsabilidade" é uma categoria relacional por excelência, um valor ético-moral que articula os planos físico e moral da doença alcoólica. À imagem do "homem descompromissado", "dependente do álcool" e que tem sua vontade dominada pela bebida, contrapõe-se a imagem do "homem responsável", 
membro de AA, que se responsabiliza pelos cuidados de si mesmo, ao mesmo tempo que cumpre seus deveres em relação à sua família.

O modelo terapêutico de AA possibilita, então, a reconstrução da subjetividade, através da incorporação da doença alcoólica como a alteridade necessária à fabricação da identidade de "doente alcoólico em recuperação". O modelo de AA é um constructo simbólico que opera no registro da subjetivação da doença, permitindo ao alcoólico reconhecer-se como doente, ao mesmo tempo que se baseia em uma terapêutica englobada pela lógica cultural regida pelos valores "família" e "trabalho".

Nessa linha, a recuperação de um alcoólico significa também a recuperação de seus laços familiares. A reconstrução subjetiva também envolve o resgate das identidades sociais de pai/mãe, esposo(a) e trabalhador(a), dentro de uma lógica regida por códigos culturais, através dos quais articulam-se os planos físico e moral da vida do alcoólico.

Assim, se o modelo terapêutico da irmandade visa restabelecer a responsabilidade do alcoólico no cuidado de si, através da abstinência em relação ao álcool, ele também possibilita o "cuidado do Outro", através da restauração das relações familiares e profissionais.

É assim que, todos os dias, os AAs celebram a sobriedade e identificam-se como "doentes alcoólicos em recuperação", responsáveis pelos cuidados de si mesmos e de suas famílias, (re)desenhando, dessa maneira, os contornos de sua construção subjetiva dentro de um modelo terapêutico no qual relacionar-se com o outro significa, fundamentalmente, um voltar-se para si mesmo.

\section{BIBLIOGRAFIA}

ALCOÓliCOS ANÔNIMOS, 1994, A História de como Milhares de Homens e Mulheres se Recuperaram do Alcoolismo. São Paulo, Centro de Distribuição de Literatura de AA para o Brasil.

—, 1996, O Grupo de AA: Onde Tudo Começa. São Paulo, Junta de Serviços Gerais de Alcoólicos Anônimos.

— 2001, Os Doze Passos e as Doze Tradições. São Paulo, Junta de Serviços Gerais de Alcoólicos Anônimos.

BATESON, Gregory, 1977, “La cybernétique de 'soi': une théorie de l'alcoolisme”, em Gregory Bateson, Vers une écologie de l'esprit: 1. Paris, Seuil, 225-252.

BERNAND, Carmen, 2000, "Boissons, ivresses et transitions", Revue Autrement, 191: 13-53.

CAMPOS, Edemilson Antunes de, 2005a, Alcoolismo, Doença e Pessoa: Uma Etnografia da Associação de Ex-bebedores Alcoólicos Anônimos. São Carlos, Universidade Federal de São Carlos, tese de doutorado. 
CAMPOS, Edemilson Antunes de, 2005b, “Contágio, doença e evitação em uma associação de ex-bebedores: o caso dos Alcoólicos Anônimos”, Revista de Antropologia, 48 (1): 315-361.

CEBRID, 2006, II Levantamento Domiciliar sobre Uso de Drogas Psicotrópicas no Brasil: Estudo Envolvendo as 108 Maiores Cidades do País - 2005, São Paulo, Universidade Federal de São Paulo/Senad.

DUARTE, Luiz Fernando Dias, 1986, Da Vida Nervosa da Classe Trabalhadora. Rio de Janeiro, Jorge Zahar Editor.

—_, 2003, "Indivíduo e pessoa na experiência da doença", Ciência e Saúde Coletiva, 8 (1): 173-183. DUFOUR, Annie Hélène, 1989, "Cafés des hommes en Provence", Terrain, 13: 81-86.

FAINZANG, Sylvie, 1996, Ethnologie des anciens alcooliques: la liberté ou la mort. Paris, PUF. FASSIN, Didier, 1996, L'espace politique de la santé: essais de généalogie. Paris, PUF.

GARCIA, Angela Maria, 2004, E o Verbo (Re)fez o Homem: Estudo do Processo de Conversão do Alcoólico Ativo em Alcoólico Passivo. Niterói, Intertexto.

GUEDES, Simone Lahud, 1997, Jogo de Corpo: Um Estudo de Construção Social de Trabalhadores. Rio de Janeiro, EDUFF.

MACHADO DA SILVA, Luiz Antonio, 1978, “O significado do botequim”, em L. Kowarick (org.), Cidade: Usos \& Abusos. São Paulo, Brasiliense, 77-1 14.

MAGNANI, José Guilherme Cantor, 2003, Festa no Pedaço: Cultura Popular e Lazer na Cidade. São Paulo, Huicitec, 3. ${ }^{\mathrm{a}}$ ed.

MOTA, Leonardo Araújo, 2004, A Dádiva da Sobriedade: A Ajuda Mútua nos Grupos de Alcoólicos Anônimos. São Paulo, Paulus.

NEVES, Delma Pessanha, 2004, “Alcoolismo: acusação ou diagnóstico?”, Cadernos de Saúde Públicai, 20 (1): 7-14.

SAHLINS, Marshall, 2003a, Cultura e Razão Prática. Rio de Janeiro, Jorge Zahar Editor, trad. Sérgio Tadeu de Niemayer.

— $2003 \mathrm{~b}$, Ilhas de História. Rio de Janeiro, Jorge Zahar Editor, trad. Barbara Sette.

SALIBA, Chalif, 1982, La cure de désintoxication alcoolique et ses prolongements. Lyon, Presses Universitaires de Lyon.

SARTI, Cynthia Andersen, 2005, A Família como Espelho: Um Estudo sobre a Moral dos Pobres. São Paulo, Cortez Editora, 3. ${ }^{\mathrm{a}}$ ed.

SOARES, Barbara Musumeci, 1999, Mulheres Invisíveis: Violência Conjugal e Novas Políticas de Segurança. Rio de Janeiro, Civilização Brasileira.

Alcoholism: illness and meaning in Alcoholics Anonymous - Edemilson Antunes de Campos • Universidade de São Paulo • edicampos@usp.br

The purpose of this article is to understand the therapeutic model of the Alcoholics Anonymous (AA) to approach the so-called alcoholism illness by means of an analysis of cultural codes that operate in the health-illness process. Starting from an ethnographic research made among AA groups located in the outskirts of the city of São Paulo - Brazil -, an analysis is made on the meanings attributed to the experience of alcoholism, with stress on the language that allows alcoholics to find a meaning for their afflictions. The AA model operates the symbolic construction of the alcoholic illness. This way, alcoholics find a meaning for the evil that afflicts them and recover family and professional relationships lost in the times of active alcoholism.

KEYWORDS: Alcoholics Anonymous, alcoholism, culture, self-help groups, health-illness process. 